\title{
Photochemistry of cyclopentadienylthallium(I)*
}

\author{
Horst Kunkely and Arnd Vogler \\ Institut für Anorganische Chemie, Universität Regensburg, Universitätsstr. 31, W-8400 Regensburg (Germany)
}

(Received April 14, 1993)

\begin{abstract}
$\mathrm{TlC}_{5} \mathrm{H}_{5}$ displays absorption maxima at 228 and $280 \mathrm{~nm}$ which are assigned to metal-centred sp and ligand-to-metal charge transfer (LMCT) transitions, respectively. The complex shows an emission at $\lambda_{\max }=360 \mathrm{~nm}$ which originates from a low-energy sp excited state. The photolysis of $\mathrm{TIC}_{5} \mathrm{H}_{5}$ in methanol proceeds according to the equation $\mathrm{TlC}_{5} \mathrm{H}_{5}+\mathrm{CH}_{3} \mathrm{OH} \rightarrow \mathrm{TlOH}+\mathrm{H}_{2}+\mathrm{C}_{6} \mathrm{H}_{6}$ (pentafulvene) with $\phi=0.1$ at $\lambda_{\mathrm{irr}}=254 \mathrm{~nm}$ and 0.008 at $313 \mathrm{~nm}$. It is suggested that this photoreaction is induced by LMCT excitation.
\end{abstract}

\section{Introduction}

While the photochemistry of transition metal complexes with aromatic ligands such as benzene or the cyclopentadienyl anion $\left(\mathrm{C}_{5} \mathrm{H}_{5}{ }^{-}=\mathrm{Cp}^{-}\right)$has been studied extensively for many years [1,2] light-induced processes of organometallic compounds of main group metals with such ligands have been completely ignored. A few years ago we started a systematic investigation of the photochemistry of main group metal complexes in general [3-5]. In the meantime we revealed some important features of the excitcd states of main group metal complexes with simple ligands such as chloride. The present study proceeds one step further and combines the photochemistry of coordination compounds of the main group metals and organometallics with aromatic ligands which utilize their $\pi$-electrons for metal-ligand bonding. This photochemistry should not only be interesting in its own right but may also lead to important applications such as $\mathrm{C}-\mathrm{C}$ or $\mathrm{C}-\mathrm{H}$ bond activation. In this context it is quite intriguing that atomic mercury which has the same electronic structure as $\mathrm{Tl}^{+}$photosensitizes the dehydrodimerization of organic compounds in solution [6,7] and in the gas phase [8].

\footnotetext{
Correspondence to: Prof. Dr. A. Vogler.

* Dedicated to Prof. Dr. Dr. h. c. mult. Ernst Otto Fischer, on the occasion of his 75 th birthday.
}

Suitable candidates for the present study are cyclopentadienyl [9] or benzene [10] complexes of $s^{2}$ metals such as $\mathrm{Ga}^{+}, \mathrm{In}^{+}, \mathrm{Tl}^{+}, \mathrm{Ge}^{2+}, \mathrm{Sn}^{2+}, \mathrm{Pb}^{2+}, \mathrm{Sb}^{3+}$ or $\mathrm{Bi}^{3+}$. We selected the complex TlCp which had first been prepared by Fischer in 1957 [11,12]. This compound offers several advantages. It is easily prepared [13] or commercially available. Moreover, TlCp is surprisingly stable toward hydrolysis and oxidation by oxygen. Owing to these properties TlCp has been used extensively as a versatile reagent in organometallic synthesis [13].

\section{Experimental details}

$\mathrm{TlC}_{5} \mathrm{H}_{5}$ was purchased from Aldrich and purified by sublimation. Methanol was spectrograde.

The light source was a Hanovia $\mathrm{Xe} / \mathrm{Hg} 977 \mathrm{~B}-1$ $(1000 \mathrm{~W})$ lamp. Monochromatic light $\left(\lambda_{\text {irr }}=254\right.$ and $313 \mathrm{~nm}$ ) was obtained by means of a Schoeffel GM 250-1 high-intensity monochromator. The photolyses were carried out at room temperature in $1 \mathrm{~cm}$ spectrophotometer cells. For quantum yield determinations the complex concentrations were such as to have essentially complete light-absorption. The total amount of photolysis was limited to less than $5 \%$ to avoid light absorption by the photoproduct. Absorbed light intensities were determined by a Polytec pyroelectric radiometer, which was calibrated and equipped with a RkP-345 detector. 


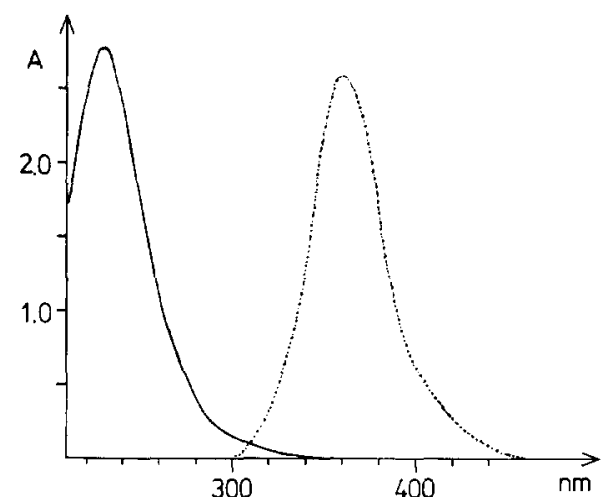

Fig. 1. Electronic absorption (left side) and emission (right side) spectra of $\mathrm{TIC}_{5} \mathrm{H}_{5}$ in methanol at room temperature, $1 \mathrm{~cm}$ cell. Absorption: $3.57 \times 10^{-4} \mathrm{M}$. Emission: $1.78 \times 10^{-4} \mathrm{M}, \lambda_{\mathrm{exc}}=250 \mathrm{~nm}$, intensity in arbitrary units.

Progress of photolysis was monitored by UV-visible spectrophotometry, using a 8452 Hewlett Packard diode array spectrophotometer.

\section{Results}

TICp is moderately soluble in polar organic solvents. For spectroscopic and photochemical studies methanol is a suitable solvent since it is transparent in the UV region. The electronic spectrum of TlCp (Fig. 1) consists of an absorption maximum at $\lambda=228 \mathrm{~nm}(\epsilon=$ $\left.7800 \mathrm{M}^{-1} \mathrm{~cm}^{-1}\right)$ and a shoulder at $\lambda c a .280 \mathrm{~nm}$ $(\epsilon=1100)$. Solutions of TICp in methanol were also emissive. A luminescence appeared at $\lambda_{\max }=360 \mathrm{~nm}$ (Fig. 1) with a quantum yield of approximately $10^{-3}$. The excitation spectrum agreed well with the absorption spectrum including the long-wavelength shoulder.

Upon irradiation of $\mathrm{TICp}$ in $\mathrm{CH}_{3} \mathrm{OH}$ photolysis took place which led to the release of hydroxide as indicated by an increase of the $\mathrm{pH}$. In addition hydrogen was detected by gas chromatography. The photolysis was accompanied by spectral variations (Fig. 2) which gave clear evidence for the formation of pentafulvene $\mathrm{C}_{6} \mathrm{H}_{6}$ $\left(\lambda_{\max }=362 \mathrm{~nm}, \epsilon=230 ; \lambda_{\max }=242 \mathrm{~nm}, \epsilon=11400\right)$ [14]. Since at the isosbestic points at 267 and $220 \mathrm{~nm}$ the extinction coefficients of TICp and pentafulvene are roughly equal, the photolysis of TICp generated fulvene in a 1:1 stoichiometry. The quantum yield for the formation of fulvene was dependent on the wavelength of irradiation $(\phi=0.1$ at $254 \mathrm{~nm}$ and 0.008 at $313 \mathrm{~nm}$ ). At later stages of the photolysis the isosbestic points were lost indicating secondary processes.

\section{Discussion}

The bonding in TlCp (and InCp) has been discussed extensively [15-19]. From these calculations a simple

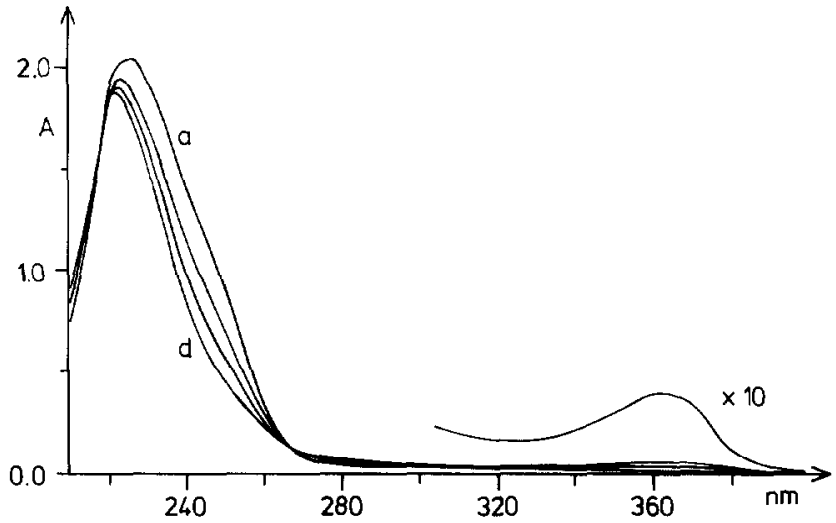

Fig. 2. Spectral changes during the photolysis of $2.58 \times 10^{-4} \mathrm{M}$ $\mathrm{TiC}_{5} \mathrm{H}_{5}$ in methanol at (a) $0 \mathrm{~min}$ and (d) $4 \mathrm{~min}$ irradiation time with $\lambda_{\text {irr }}=254 \mathrm{~nm}$ and a $1 \mathrm{~cm}$ cell.

MO scheme can be derived (Fig. 3). The most important MOs including the frontier orbitals are generated by the interaction of the $s$ and $p$ valence orbitals of the metal with the bonding $\pi$-orbitals of $\mathrm{Cp}^{-}$. In this context it is interesting to note that the bonding in TICp is quite similar to that in $\mathrm{MCl}_{3}{ }^{-}$with $\mathrm{M}=\mathrm{Ge}, \mathrm{Sn}$ and $\mathrm{Pb}[5,20]$. According to Fig. 3 the longest-wavelength absorption of TICp at $\lambda_{\max }=280 \mathrm{~nm}$ is assigned to the metal-centred $a_{1} \rightarrow a_{1}{ }^{*}, e_{1}{ }^{*} \mathrm{sp}$ transition from the lone pair at $\mathrm{Tl}^{+}$to the empty p-orbitals of the metal. It corresponds to the ${ }^{1} \mathrm{~S}_{0} \rightarrow{ }^{3} \mathrm{P}_{1} \mathrm{sp}$ transition of the free $\mathrm{Tl}^{+}$ion [3-5]. This assignment is supported by the appearance of the luminescence of TICp since an emission is expected to show up only if sp transitions occur at lower energies than other transitions of different origin [3-5]. The more intense absorption of TICp at $\lambda_{\max }=228 \mathrm{~nm}$ is then assigned to the ligand-to-metal charge transfer (LMCT) transition $\mathrm{e}_{1} \rightarrow \mathrm{a}_{1}{ }^{*}, \mathrm{e}_{1}{ }^{*}$ (Fig.

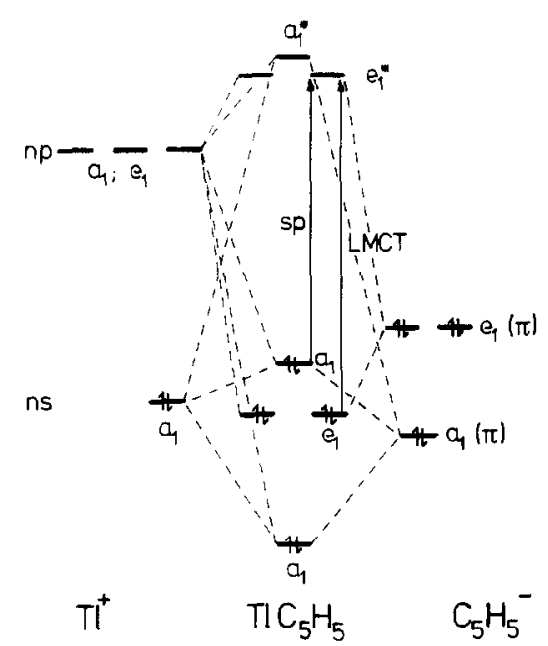

Fig. 3. Qualitative MO scheme of $\mathrm{TlC}_{5} \mathrm{H}_{5}\left(C_{5 v}\right.$ symmetry). 
3) from the $\mathrm{Cp}^{-}$ligand into the empty p-orbitals of thallium. It should be mentioned that the nature of the HOMO has been discussed amid some controversy. It was assumed to be either the $a_{1}$ lone pair $[17,19]$ or the degenerate $e_{1}$ ligand orbital $[15,18]$. In the light of our results we prefer an $a_{1}$ assignment for the HOMO. However, both orbitals $\mathrm{a}_{1}$ (lone pair) and $\mathrm{e}_{1}\left(\mathrm{Cp}^{-}\right)$are certainly close in energy.

The emission of TlCp at $\lambda_{\max }=360 \mathrm{~nm}$ is assumed to originate from the lowest sp excited state $\left({ }^{3} \mathrm{P}_{1}\right.$ of free $\left.\mathrm{Tl}^{+}\right)$. The Stokes shift of this spin-forbidden transition is relatively small $\left(\Delta \bar{\nu} c a .8000 \mathrm{~cm}^{-1}\right)$ indicating moderate structural changes in the excited state. This observation is not surprising since in distinction to other three-coordinate $\mathrm{s}^{2}$ complexes such as $\mathrm{MCl}_{3}{ }^{-}$ $(\mathrm{M}=\mathrm{Ge}, \mathrm{Sn}$ and $\mathrm{Pb})[5,20]$ TlCp cannot be transformed to a planar structure.

The photolysis of TlCp is assumed to be induced by $\mathrm{e}_{1} \rightarrow \mathrm{a}_{1}{ }^{*}, \mathrm{e}_{1}{ }^{*}\left(\mathrm{Cp}^{-}\right.$to $\left.\mathrm{Tl}^{+}\right) \mathrm{LMCT}$ excitation since the reaction is most efficient upon light absorption by the CT band. The appearance of the metal-centred luminescence and the lower photochemical quantum yield upon irradiation into the sp absorption at longer wavelength suggest that the reactive LMCT state can be also populated from the cmitting sp state by an activated process. Similar arguments were used to explain the wavelength-dependent quantum yields for the reductive elimination of $\mathrm{TeBr}_{6}{ }^{2-}$ [21].

The photolysis of TICp in methanol can be described by the equation:

$\mathrm{TlCp}+\mathrm{CH}_{3} \mathrm{OH} \stackrel{h \nu}{\longrightarrow} \mathrm{TIOH}+\mathrm{H}_{2}+\square=$

This reaction seems to be quite unique. At the moment we can offer only a tentative explanation. In the LMCT state TICp roughly consists of a thallium atom and a $\mathrm{Cp}$ radical. This radical pair is certainly very reactive and could attack the solvent in the primary photochemical step. The primary products and the subsequent processes may be identified by further studies including flash photolysis and low-temperature spectroscopy.

As a final remark we would like to point out the potential of this photoreaction for a photocatalytic conversion of cyclopentadiene and methanol to pentafulvene. This idea is based on the fact that $\mathrm{TlOH}$ which is one of the photoproducts is well known to yield TICp thermally by its reaction with cyclopentadiene [13]. It may be necessary to carry out such a photocatalysis by a phase transfer photolysis [22] because fulvene seems itself to be light-sensitive. In order to prevent a secondary photolysis of fulvene it must be accumulated in a separate phase which is kept in the dark.

\section{Acknowledgments}

Support of this research by the BMFT (grant 0329075 A) and the Fonds der Chemischen Industrie is gratefully acknowledged.

\section{References}

1 G.L. Geoffroy and M.S. Wrighton, Organometallic Photochemistry, Academic Press, New York, 1979.

2 R.E. Bozak, Adv. Photochem., 8 (1971) 227.

3 A. Vogler, A. Paukner and H. Kunkely, Coord. Chem. Rev., 57 (1990) 285.

4 A. Vogler and H. Nikol, Pure Appl. Chem., 64 (1992) 1311.

5 A. Vogler and H. Nikol, Comments Inorg. Chem., 14 (1993) 245.

6 R.R. Kuntz and G.J. Mains, J. Am. Chem. Soc., 85 (1963) 2219.

7 J.G. Calvert and J.N. Pitts, Photochemistry, Wiley, New York, 1966.

8 S.H. Brown and R.H. Crabtree, J. Am. Chem. Soc., 111 (1989) 2935 and 2946.

9 (a) P. Jutzi, J. Organomet. Chem., 400 (1990) 1; (b) P. Jutzi, Chem. Rev., 86 (1986) 894; (c) P. Jutzi, Adv. Organomet. Chem., 26 (1986) 217.

10 (a) H. Schmidbaur, Angew. Chem., 97 (1985) 893; Angew. Chem., Int. Ed. Engl., 24 (1985) 893; (b) H. Schmidbaur, R. Nowak, O. Steigclmann and G. Müller, Chem. Ber., 123 (1990) 1221 and references cited therein.

11 E.O. Fischer, Angew. Chem., 69 (1957) 207.

12 E.O. Fischer and H.P. Hofmann, Angew. Chem., 69 (1957) 639.

13 H. Kurosawa, Thallium in G. Wilkinson, F.G.A. Stone and E.W. Abel, (eds.), Comprehensive Organometallic Chemistry, Vol. 1, Pergamon, Oxford, 1982, p. 725.

14 D. Meuche, M. Neuenschwander, H. Schaltegger and H.U. Schlunegger, Helv. Chim. Acta, 47 (1964) 1211.

15 S. Cradock and W. Duncan, J. Chem. Soc., Faraday Trans., 2, 74 (1978) 194.

16 R.G. Edgell, I. Fragala and A.F. Orchard, J. Electron. Spectrosc. Relat. Phenom., 14 (1978) 467.

17 C.S. Lin and D.G. Tuck, Can. J. Chem., 60 (1982) 699.

18 E. Canadell and O Eisenstein, Organometallics, 3 (1984) 759.

19 P.H.M. Budzelaar and J. Boersma, Recl. Trav. Chim. Pays-Bas, 109 (1990) 187.

20 H. Nikol, A. Becht and A. Vogler, Inorg. Chem., 31 (1992) 3277.

21 A. Vogler and A. Paukner, I. Photochem. Photobiol. A: Chem., 46 (1989) 227.

22 H. Kunkely and A. Vogler, Organometallics, 11 (1992) 3172. 